\title{
Research on Risk Management of Logistics Material Purchase
}

\author{
Jianjun Han, Xiaolan Lu \\ Logistics University of People's Armed Police Force \\ Tianjin, P.R. China \\ 1600644691@qq.com
}

\begin{abstract}
The main way at the sudden mobilization of logistical supplies are material procurement, with increasing force material procurement scale, increased activity, new materials procurement situation forces faced new problems emerging, risk exposure is also increasing. This paper first puts forward the risk aversion, risk control, risk transfer, risk dispersion and risk bearing risk approach. Second, make full use of the risk treatment technology, establish a risk management decision model, put forward on the procurement risk of one-time static model and general handling. And in the risk management static model has been established on the basis of, according to the variation of material procurement risk monitoring and adjust accordingly, established the dynamic model of risk treatment decisions.
\end{abstract}

\section{Keywords-logistic;material;purchase;risk;prevention}

\section{RISK MANAGEMENT APPROACH}

\section{A. Risk Aversion}

Risk aversion is mainly to interrupt the risk sources, so that the risk cannot happen or contain its development [29]. Risk aversion may sometimes have to make some necessary sacrifices, but it is more likely to be less likely to be lost than the real risk of the risk, or even trivial, such as the risk of small or moderate projects. Therefore, in the risk management should pay attention, to give up a significant result in the loss of the project. For the risk of more than their ability to bear, and the success of the project, not to implement. Even in the material procurement projects to be carried out in half, the forecast to the late risk is great, there may be a greater loss, it should take measures to interrupt the project.

\section{B. Risk Control}

Risk control is to reduce the risk of loss of opportunity or reduce the severity of the loss, to minimize the risk of loss. Mainly include the following two aspects of the work:

One is to prevent loss. Prevention is to take preventive measures to prevent the occurrence of losses. E.g. supplier by expanding the supply channels to avoid unsalable goods; the Contractor through improve quality control standards to prevent substandard quality and rework or fine; production management personnel through strengthen safety education and strengthen the safety measures and reduce the chance of accident etc.. In the procurement of goods and materials, the procurement department is often the loss prevention as an important matter.

Two is to reduce the loss. Reducing losses means that the loss of the risk is inevitable, and through a variety of measures to curb the loss continues to deteriorate or limit its spread, it is said that the loss of localization. Control loss should be based on prevention, prevention and control of the combination, should be careful study of the source of the risk of material procurement. In the case of a specific procurement project, we should carry out the corresponding loss control analysis in the planning, execution, and so on.

\section{Risk Transfe}

Risk transfer is another means of risk control, which means that the Logistics Department of armed police forces will be the result of a risk in the procurement of goods and the corresponding risk corresponding to the rights and responsibilities transferred to the third party. Risk transfer mechanism is to change the risk of the main body, the Armed Police Force Procurement Department is a risk event, and by the third party to complete the risk is not necessarily a risk event, or the amount of risk has been greatly reduced.

The methods used in risk transfer are: transfer of contract conditions and insurance. For example, the armed police force in the procurement of logistics materials, due to the asymmetry of market information, the procurement department of the quality of the procurement of goods can not be accurately mastered, will produce material procurement quality risk. And if in the contract with the supplier, the supplier shall be responsible for the loss caused by the poor quality of the material quality. For the supplier, he has the full information on the quality of the material, so the material quality is not a risk event for him.

\section{Risk Dispersion}

Risk diversification and risk transfer is not the same, the latter is the risk of a unit to another unit, and risk diversification is the risk sharing between units and units. The total risk of a material procurement project is in a certain range, and these risks must be allocated between the procurement project participants (e.g., the purchasing department and the supplier). Each participant must take a certain risk responsibility, so that he can have the enthusiasm and creativity of management and control. Risk allocation is usually defined in the task book, Liability Certificate, contract, tender documents, etc., in the drafting of these documents to respond to the risk to make a forecast, definition and distribution. Only the reasonable allocation of risk, in order to mobilize the enthusiasm of all aspects, to have a project of high efficiency. 


\section{E. Risk Taking}

Risk taking, also known as risk acceptance, is a risk response strategy for the procurement department of the armed police force to bear the consequences of the risk. This strategy means that the purchasing department does not change the security plan to deal with a certain risk; or the procurement department should not find a way to cope with the risk of other appropriate risk response strategies. When the probability of the occurrence of risk events is very low, or the loss caused by the risk in the planned limit, or eliminate the risk of the risk may be higher than or equivalent to the loss caused by the risk event, it is appropriate to take the risk taking strategy.

\section{RISK MANAGEMENT DECISION-MAKING MODEL}

The handling of the risk of military material procurement must have a sound decision-making plan. According to the risk identification and assessment of the military material procurement, we can make full use of the technology of risk management and establish the decisionmaking model of risk management.

\section{A. static mode}

Static model refers to the one-time and general treatment of the risk of material procurement. According to the evaluation results, the decision model can be expressed in Fig .1:

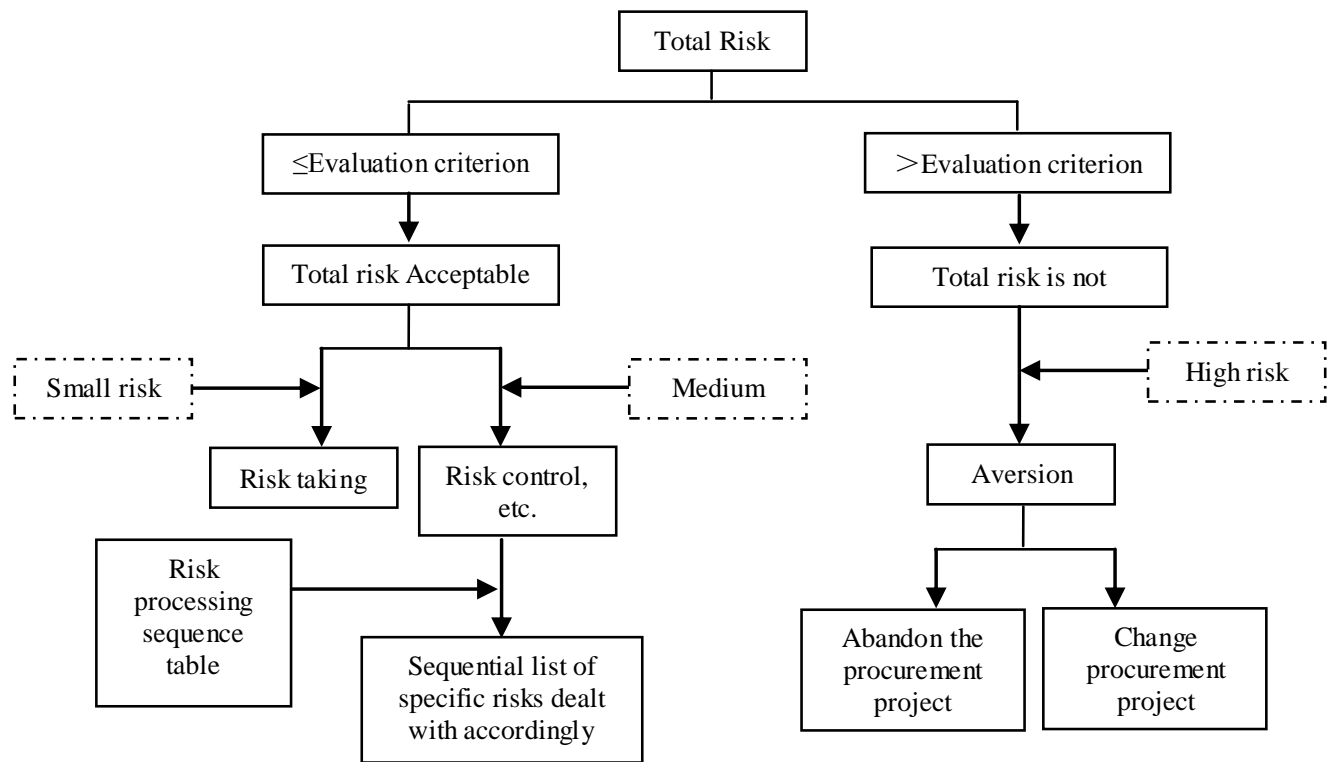

Figure 1. Risk Decision Model

As shown in figure, if the total risk level of material procurement (i.e., risk assessment results) is greater than the evaluation criteria, and beyond the scope of the force, the total risk is not acceptable, should take the risk averse treatment technology, in accordance with the actual situation to abandon the procurement project or change the procurement objectives and action plan.

If the total risk of material procurement is less than or equal to the evaluation criteria, the total risk may be acceptable within the acceptable range. At this point, the wind is very small, and the loss of material procurement may be small, you can take the risk of processing technology, in order to reduce the cost of risk management. Such as the risk of moderate (including the risk of small, moderate or large), you can use risk control, risk transfer and other processing techniques, and according to the risk treatment sequence table for each specific risk in order to deal with, to reduce the risk of material procurement.

\section{1) Risk Management Decision-making Model} Conditions: The aim of the armed police force material procurement risk management is to reduce the risk and reduce the loss. If taken in the risk management strategies in dealing with risks of the consumption cost is greater than take this strategy can reduce the risk of loss, is not worth the candle. Therefore, it is a prerequisite to meet the cost benefit principle of [30] as a prerequisite for risk management. The concrete description can be shown in Fig .2:

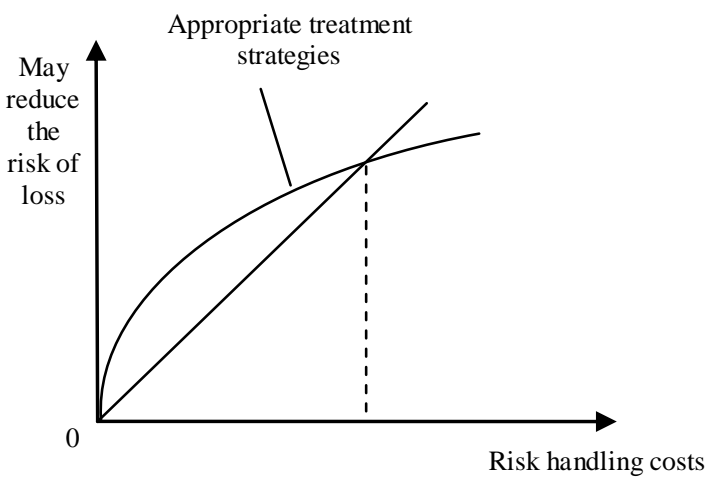

Figure 2. Figure constraints risk management decisions

By the law of diminishing marginal benefit, with the increase of the cost of risk treatment, the effect of the treatment cost per unit (which reduces the risk of loss) is reduced, and the cost of risk management will exceed the loss of the cost. Therefore, in the risk management, we should pay attention to meet: "risk management costs can 
be reduced by the risk of loss," the premise constraint conditions, with smaller costs to achieve greater benefits, such as in the risk management of material procurement, when found with the operation, processing into this has been close to or more than can be reduced, should immediately stop this measure, to switch to other methods.

2) the establishment of risk treatment sequence table: In the process of material purchase risk management decision-making model, risk treatment sequence table is a very important position.

Here, the establishment of the sequence table is mainly dependent on an important concept - the importance of risk. The risk importance is the impact of a certain risk to the entire material procurement project, based on the consideration of the factors such as the risk level and the severity of the loss. Here, it can be quantified, the following formula:

$$
M_{i j}=Q_{i j} \times E_{i j}
$$

Here at the three level of risk for the object, $M_{i j}$ stands for the importance of a risk; $Q_{i j}$ means to evaluate the risk level of the risk score $\left(Q_{i j}=B_{i j} \cdot P\right.$ ); $E_{i j}$ stands for he risk of loss, which refers to the severity of the risk assessment evaluation value (ie, the evaluation of the risk of loss expectations).

By the formula, we can get the quantitative value of the risk importance. By the order of large to small order, so as to establish a list of the original risk treatment sequence:

$$
M: M^{1} \geq M^{2} \geq M^{3} \cdots \geq M^{n}
$$

In the specific risk treatment, may use this as a prototype, considering the degree of difficulty of risk management, risk management needs, the risk management of feasibility and other factors, make the appropriate adjustments in order to establish for the military material procurement risk management

$$
M_{0}: \bar{M}^{1} \geq \bar{M}^{2} \geq \bar{M}^{3} \ldots \geq \bar{M}^{n}
$$

\section{B. Dynamic Model}

The risk of military material procurement is affected by the factors of various aspects in the process of purchasing. Based on the model of risk management and decision making, the dynamic model of risk management decision making is set up according to the change of material purchasing.

1) Risk Monitoring: Risk monitoring is an important work in the process of material purchase. Monitoring risk is the progress of material procurement and procurement environment, that is, the change of purchasing variables. The purpose is to check whether the actual effect of risk management strategies and measures is the same as that of the forecast, to find the opportunity to improve and refine the procurement risk management decision-making; to obtain feedback information, so that the future decision to implement more practical., we must remain vigilant in monitoring risk, early detection risk of the new and pre established policies or measures not effective or properties change with time delays, the cause of loss of control. To this end, the time and resources to allow the premise, to the full track of its risk management process, and at the same time to record the results of the evaluation, and regularly compiled into a risk monitoring document, so that the risk management personnel and procurement decision making personnel. The main contents of the general risk monitoring can include the following aspects: first, the risk identification of monitoring material procurement; two is tracking risk assessment; three is the development of risk monitoring standards; four is the use of effective risk monitoring methods, such as audit inspection, monitoring, cost deviation analysis method, etc.; six is the evaluation and management strategy; five is to record and report risk state, etc.

2) Risk Adjustment: Regardless of whether the decision making strategy is put into practice or not, the risk monitoring is essential. In the process of material procurement, through monitoring, such as the discovery of the risk management decision-making is wrong, it must be recognized as soon as possible to take immediate action to correct. Such as processing decision-making correctly, but the effect is not good, then should not be eager to change the decision has been set. This decision may be the best decision for the purchasing department, but it may be the best decision to implement. At the same time, the frequent change of mind, not only will reduce the emergency use of reserve resources, but also greatly increase the possibility of the occurrence of risk events after the purchase of material, increase the adverse consequences. In order to be cautious, the general risk adjustment should be based on the premise of considering the actual situation of material procurement, the results based on the results of risk monitoring carefully. In the actual adjustment, the feedback information obtained from the monitoring process can be used to evaluate the original risk treatment strategy, and then evaluate the risk, and then adjust the process. If a risk from high risk to low risk and low risk, can consider to take measures of risk retention and low consumption of resources, if a risk from low risk to high risk, need to consider to take a loss control, separation of risk, risk transfer measures to control risk; if the situation becomes urgent, but also take risk reserve measures to correct it.

3) The Establishment of The Model: Based on the above risk monitoring and adjustment theory, the model of risk management decision-making is based on the static model, and the use of risk management sequence table, a dynamic model (monitoring and adjustment model) is constructed.

First, according to the risk treatment sequence table, the listed risk are included in the scope of monitoring, according to their importance, according to the "two eight law" division level. The "two eight law" also called the "Pareto principle", is at the end of nineteenth Century twentieth Century in Italy at the beginning of the invention of the economist bale. In his view, in any group of things, the most important only one small part, about $20 \%$, and the remaining $80 \%$, although it is the majority, but it is secondary, so it is called the two eight rule. Similarly, in the armed police forces material procurement in the $20 \%$ 
of the risk posed a serious threat to the procurement of $80 \%$, this small part of the possible loss is much greater than the sum of the rest of the risk. Therefore, according to the risk processing sequence table to select the most important risk for the first level (risk importance and greater than or equal to $80 \%$ ) as a key monitoring objects, most of the resources to tilt, continued to maintain longterm monitoring, to implement regular monitoring; the remainder of the risk to the second level, just spend a small amount of resources, take checks and other forms, to implement a monitoring interval. Design on behalf of the $\mathrm{dn} \%$ risk of $\mathrm{N}$ importance for all risk importance and proportion, which represents a risk risk treatment in a sequence table is one of the most important risk and risk 2 representatives of risk treatment sequence list ranked the second risk, followed by the rest of push down, as shown in Table 1 below:

TABLE I. LEVELS OF RISK MONITORING

\begin{tabular}{|c|c|c|c|}
\hline Level & Risk & Cumulative risk importance & Monitor \\
\hline \multirow{5}{*}{$\begin{array}{l}\text { First } \\
\text { level }\end{array}$} & Risk 1 & $\mathrm{~d} 1 \%<80 \%$ & \multirow{5}{*}{$\begin{array}{l}\text { Recurrent, } \\
\text { focus } \\
\text { monitoring }\end{array}$} \\
\hline & Risk 2 & $(\mathrm{~d} 1+\mathrm{d} 2) \%<80 \%$ & \\
\hline & $\vdots$ & $\vdots$ & \\
\hline & Risk n-1 & $(\mathrm{d} 1+\mathrm{d} 2+\ldots+\mathrm{dn}-1) \%<80 \%$ & \\
\hline & Risk n & $(\mathrm{d} 1+\mathrm{d} 2+\ldots+\mathrm{dn}) \% \geqslant 80 \%$ & \\
\hline \multirow{3}{*}{$\begin{array}{l}\text { Second } \\
\text { levels }\end{array}$} & $\begin{array}{l}\text { Risk } \\
\mathrm{n}+1\end{array}$ & $(\mathrm{~d} 1+\mathrm{d} 2+\ldots+\mathrm{dn}+\mathrm{dn}+1) \%>80 \%$ & \multirow{3}{*}{$\begin{array}{c}\text { Interval, } \\
\text { general } \\
\text { monitoring }\end{array}$} \\
\hline & $\vdots$ & $\vdots$ & \\
\hline & Risk n' & $\left(\mathrm{d} 1+\mathrm{d} 2+\ldots+\mathrm{dn}+\ldots+\mathrm{dn}^{\prime}\right) \%=100 \%$ & \\
\hline
\end{tabular}

The second step, according to the conclusion of the monitoring, adjust the risk treatment sequence table. In the procurement of goods, after a period of time, the implementation of risk management measures, all risks will have a certain change, while some of the new risk may also be exposed. At this time, we should carry out the risk assessment based on the monitoring results of this period, get the new risk level evaluation and risk loss evaluation value, and thus get the new risk importance.

$$
E_{i j} \rightarrow E_{i j}{ }^{\prime}, Q_{i j} \rightarrow Q_{i j}{ }^{\prime}, M_{i j} \rightarrow M_{i j}{ }^{\prime}=Q_{i j}{ }^{\prime} \times E_{i j}{ }^{\prime}
$$

Thus, according to the importance of the risk of re sequencing, new sequence table can be $M_{0} \rightarrow M_{1}$.

Based on this list, the risk management decision making model is adjusted. The new management strategy is adopted to update the risk management level, and the risk management resources are re deployed. In order to seize the focus and concentrate, the risk adjustment table only involves the first level of risk. If a risk project is new in the new sequence table, the risk management should be identified as the key to alert the risk, to prevent further improvement of the risk. Examples are as follows:
TABLE II.

RISK ADJUSTED SAMPLE TABLE

\begin{tabular}{|c|c|c|c|c|}
\hline $\begin{array}{c}\text { Risk } \\
\text { sequence } \\
\text { number }\end{array}$ & $\begin{array}{c}\text { Original } \\
\text { risk }\end{array}$ & $\begin{array}{c}\text { Original } \\
\text { measures }\end{array}$ & $\begin{array}{c}\text { Adjustment } \\
\text { risk }\end{array}$ & $\begin{array}{c}\text { Adjustment } \\
\text { measures }\end{array}$ \\
\hline 1 & $\begin{array}{c}\text { Acceptance } \\
\text { risk }\end{array}$ & $\begin{array}{c}\text { Risk } \\
\text { control }\end{array}$ & $\begin{array}{c}\text { Institutional } \\
\text { risk }\end{array}$ & $\begin{array}{c}\text { Backup } \\
\text { measures }\end{array}$ \\
\hline 2 & $\begin{array}{c}\text { Institutional } \\
\text { risk }\end{array}$ & $\begin{array}{c}\text { Preventing } \\
\text { loss }\end{array}$ & Moral hazard & $\begin{array}{c}\text { Reduce } \\
\text { loss }\end{array}$ \\
\hline 3 & $\begin{array}{c}\text { Moral } \\
\text { hazard }\end{array}$ & $\begin{array}{c}\text { Reduce } \\
\text { loss }\end{array}$ & $\begin{array}{c}\text { Supervision } \\
\text { and control } \\
\text { risk }\end{array}$ & $\begin{array}{c}\text { Risk } \\
\text { control }\end{array}$ \\
\hline$\vdots$ & $\vdots$ & $\vdots$ & $\vdots$ & $\vdots$ \\
\hline
\end{tabular}

Third step, multi wheel monitoring and adjustment. In actual material procurement, often a round of monitoring and adjustment is not enough, but also need to carry out a number of monitoring and adjustment. Here according to the size of the material purchasing and purchasing time, divided into rounds of adjustment. Such as the size of the larger, longer time, the number of the adjustment wheel is more; if the smaller, the shorter the time, the number of the adjustment wheel is less, even due to the size of a small or too short, not to adjust. As shown in Table 3, the entire multi wheel monitoring and adjustment is carried out as follows:

TABLE III. RISK ADJUSTED SAMPLE TABLE

\begin{tabular}{|c|c|c|c|}
\hline $\begin{array}{c}\text { The number of } \\
\text { rounds }\end{array}$ & $\begin{array}{c}\text { Risk level } \\
\text { evaluation }\end{array}$ & $\begin{array}{c}\text { Risk loss } \\
\text { evaluation }\end{array}$ & $\begin{array}{c}\text { Risk sequence } \\
\text { table }\end{array}$ \\
\hline First round & $Q_{i j}^{\prime}$ & $E_{i j}{ }^{\prime}$ & $M_{1}$ \\
\hline Second round & $Q_{i j}{ }^{\prime \prime}$ & $E_{i j}{ }^{\prime \prime}$ & $M_{2}$ \\
\hline$\vdots$ & $\vdots$ & $\vdots$ & $\vdots$ \\
\hline F round & $Q_{i j}{ }^{f}{ }^{\prime}$ & $E_{i j}{ }^{f}{ }^{\prime}$ & $M_{f}$ \\
\hline
\end{tabular}

In this paper, the method of risk management and prevention is put forward. First of all, the way of risk management: risk aversion, risk control, risk transfer, risk diversification and risk taking. Secondly, the static model of risk management is put forward. According to the results of the risk assessment, different risk management methods are chosen. Third, the dynamic model of risk management is put forward.

\section{REFERENCES}

[1] Zhang Linhui. Introduction to enterprise procurement business risk analysis $[\mathrm{J}]$. Journal of logistics engineering and management, 2014, 12:95-98.

[2] Yu Yacheng, Shu Sheng. The risk and control measures in the process of material procurement of the Armed Police Forces [J] modern business and trade, 2015,04:48-49.

[3] Xu Xiyang, Pu Hongbo, Yuan Jianhua, Zhao Yan. Major American defense acquisition project risk assessment of new measures [J]. China Aerospace 2015,04:27-32.

[4] Zhang Lixuan. Risk prevention and control of the government procurement [D]. Changchun University of Technology, 2014

[5] Chen Liang. Study on the risk identification and avoidance strategy of aviation weapon equipment acquisition [D]. Nanchang University, 2014

[6] Chi Yuan. The internal control system and practice of the military material procurement system and practice research [D]. Dongbei University of Finance and Economics, 2014 
[7] Li Li. Risk management mechanism of enterprise internal control [J]. enterprise economy, 2012,03:52-55.

[8] Ji Jinzhen. Based on the supply chain procurement risk research [J]. Journal of logistics engineering and management, 2012, 11:110112.

[9] Zhou Pei. Reserchi on Enterprise Procurement Risk Management and Optimization Design [D]. Beijing Jiaotong University, 2015
[10] Wu Yanxun, Li Lingxiang. Study on the risk management of acquisition technology based on Grey Analytic Hierarchy Process [J]. China manufacturing industry information, 2011,23:19-22+26.

[11] Lv Chao, Hu Minxiao. Extension theory in equipment procurement risk evaluation and application of $[\mathrm{J}]$. fire control and command, 2015,09:116-120.

[12] Zhou Xiaoqi. Study on the internal control system based on risk management [D]. Northeast Normal University, 2013. 